\title{
Profissionalização e angústia: algumas reflexões sobre o suicídio nas Universidades
}

\author{
Professionalization and anguish: some reflections on suicide in Universities \\ Profesionalización y angustia: algunas reflexiones sobre el suicidio en las Universidades
}

Recebido: 06/12/2021 | Revisado: 10/12/2021 | Aceito: 15/12/2021 | Publicado: 22/12/2021

\author{
Dorisvaldo Rodrigues da Silva \\ ORCID: https://orcid.org/0000-0002-3477-9089 \\ Universidade Estadual do Oeste do Paraná, Brasil \\ E-mail: drsilva55@gmail.com \\ Vilmar Malacarne \\ ORCID: https://orcid.org/0000-0002-5222-4722 \\ Universidade Estadual do Oeste do Paraná, Brasil \\ E-mail:Vilmar.Malacarne@unioeste.br
}

\begin{abstract}
Resumo
Este texto tem por objetivo discutir e refletir sobre questões relativas ao suicídio nos espaços das universidades brasileiras. A metodologia utilizada consistiu em uma revisão de artigos disponíveis online, dados estatísticos divulgados pela Organização Mundial da Saúde, bem como informações sobre produções contidas na base de dados de Periódicos da Capes. A explanação buscou apresentar reflexões acerca de aspectos filosóficos, sociológicos e psicológicos pertinentes ao quadro de suicídio que o caracteriza como um evento de causas multifatoriais. Além disso, fez-se inserções sobre as exigências estabelecidas no contexto da universidade, bem como da relativa influência da internet como possível gatilho de start para a execução do ato suicida em adolescentes. Espera-se que o texto apresentado possa servir como reflexão e estímulo para discussões sobre o suicídio em todos os espaços sociais, a fim de criar, a partir disso, a perspectiva de desenvolver ações preventivas com o intuito de valorização e preservação da vida.
\end{abstract}

Palavras-chave: Educação; Morte; Prevenção; Preservação da vida.

\begin{abstract}
This text aims to discuss and reflect on issues related to suicide in the spaces of Brazilian universities. The methodology used consisted of a review of articles available online, statistical data released by the World Health Organization, as well as information on productions contained in the Capes Journal database. The explanation sought to present reflections on philosophical, sociological and psychological aspects relevant to the situation of suicide, which characterizes it as an event with multifactorial causes. In addition, insertions were made about the requirements established in the context of the university, as well as the relative influence of the internet as a possible start trigger for the execution of the suicidal act in adolescents. It is hoped that the text presented can serve as a reflection and stimulus for discussions about suicide in all social spaces, in order to create, from this, the perspective of developing preventive actions with the aim of valuing and preserving life.
\end{abstract}

Keywords: Education; Death; Prevention; Preservation of life.

\section{Resumen}

Este texto tiene como objetivo discutir y reflexionar sobre temas relacionados con el suicidio en los espacios de las universidades brasileñas. La metodología utilizada consistió en una revisión de artículos disponibles en línea, datos estadísticos publicados por la Organización Mundial de la Salud, así como información sobre producciones contenidas en la base de datos de Capes Journal. La explicación buscó presentar reflexiones sobre aspectos filosóficos, sociológicos y psicológicos relevantes a la situación de suicidio, que lo caracteriza como un evento con causas multifactoriales. Además, se hicieron inserciones sobre los requisitos establecidos en el contexto de la universidad, así como la influencia relativa de internet como posible detonante de inicio para la ejecución del acto suicida en adolescentes. Se espera que el texto presentado pueda servir de reflexión y estímulo para las discusiones sobre el suicidio en todos los espacios sociales, con el fin de crear, desde esto, la perspectiva de desarrollar acciones preventivas con el objetivo de valorar y preservar la vida.

Palabras clave: Educación; Muerte; Prevención; Preservación de la vida.

\section{Introdução}

Os índices de suicídio em todo o mundo têm despertado a atenção da Organização Mundial de Saúde (OMS) que, desde 2003, vem produzindo documentos com o intuito de promover campanhas de prevenção acerca do tema. A primeira 
campanha, em parceria com a Associação Internacional para a Prevenção do Suicídio (IASP), foi desencadeada em 2003 por meio da elaboração do relatório intitulado 'O suicídio pode ser evitado' e a última, em 2018, com o título 'Trabalhando junto para prevenir o suicídio'.

No Brasil, a partir de 2015, vem ocorrendo a campanha 'Setembro Amarelo' pelas iniciativas do Centro de Valorização da Vida (CVV), do Conselho Federal de Medicina e da Associação Brasileira de Psiquiatria (ANAMT, 2018) com o objetivo de conscientizar a sociedade sobre a prevenção do suicídio.

Dados apontados pela (WHO,2021) sobre a taxa de suicídios/100.000 habitantes, em 2019, traz, para a América do Sul, o seguinte panorama: Argentina (8,4), Bolívia (6,2), Brasil (6,9), Chile (9), Colômbia (3,9), Equador (7,6), Guiana (40,3), Paraguai $(6,0)$, Peru $(2,8)$, Suriname $(25,4)$, Uruguai $(21,2)$, Venezuela $(2,1)$.

O fenômeno suicídio, contudo, atinge todos os países, independentemente de suas condições de riqueza e bem-estar social. Apenas para exemplificar, estas são as taxas (de suicídios/100.000 habitantes) dos seguintes países: Estados Unidos da América (16,1), Alemanha (12,3), Portugal (11,5), Canadá (11,8), Rússia (25,1) (WHO, 2021).

Um estudo de Marín-Leon, Oliveira e Botega (2012) fez um levantamento das taxas de suicídio no Brasil no período de 2004 a 2010. Esse estudo cita as seguintes capitais com mais casos de suicídio: São Paulo, com 3.309 mortes por suicídio (taxa = 4,93); Rio de Janeiro, 1.064 (2,72); Fortaleza, 948 (6,81); Brasília, 787 (5,65); Belo Horizonte, 703 (4,73); Porto Alegre, $650(7,22)$; e Curitiba, $564(5,09)$. Na época em que foi realizada a pesquisa, os autores afirmaram que a média nacional de mortalidade por suicídio no período foi de 5,74 e que era uma taxa baixa, se comparada à média mundial.

Em 2019, nos dados apontados pela OMS - Organização Mundial de Saúde considerando a América do Sul, o brasil apresentou uma taxa de suicídio de 6,9 por 100.000 habitantes. houve crescimento de aproximadamente $20 \%$ se considerar que a taxa saiu de 5,74, em 2010, para 6,9, em 2019.

Em 2019 a OMS produziu o relatório suicide worldwide in 2019 onde apresenta que nos últimos 20 anos entre 2000 e 2019, as taxas de suicídio caíram, com a taxa global diminuindo 36\%, com diminuições variando de $17 \%$ na região do mediterrâneo oriental a 47\% na região europeia e $49 \%$ no pacífico ocidental. mas na região das américas, as taxas aumentaram 17\% no mesmo período (WHO, 2021).

Por outro lado, comparando o crescimento populacional, conforme dados (IBGE, 2018), a população do Brasil saiu de 194.890.652 de habitantes em 2010 para 210.147.125, em 2019, tendo uma taxa de crescimento em torno de 7,8\%. Neste contexto, para o período (2010-2019), enquanto o índice de crescimento populacional foi de 7,8\%, a taxa de suicídio saiu de 5,74 para $6.9 \%$ com um aumento de $20 \%$, ou seja, quase três vezes maior que o crescimento populacional.

A OMS (2018) tem como previsão que 800 mil pessoas morrem por suicídio todos os anos, sendo um fenômeno que ocorre durante toda a vida e é a segunda principal causa de morte entre os jovens de 15 a 29 anos em todo o mundo. Trata-se de um fenômeno global, que foi responsável por $1,4 \%$ de todas as mortes no mundo, tornando-se a $18^{\mathrm{a}}$ causa de morte em 2016. Diante desse quadro, a OPS - Organización Panamericana de la Salud (2014) faz os seguintes questionamentos:

O que causa o suicídio? O que leva tantas pessoas acabar com suas vidas? É a pobreza, o desemprego, a deterioração das relações, ou depressão ou outros transtornos mentais graves? Os suicídios são o resultado de um ato impulsivo ou são devidos a efeitos desinibitórios de álcool ou outras drogas? Existem muitas perguntas, mas nenhuma resposta simples. Nenhum fator é suficiente para explicar por que uma pessoa comete suicídio; o comportamento suicídio é um fenômeno complexo que é afetado por vários fatores inter-relacionados: pessoal, social, psicológico, cultural, biológico e ambiental (OPS, 2014, p. 11).

Diante desse cenário, duas questões foram as propulsoras que motivaram a exposição sobre o tema neste artigo: a leitura de uma reportagem do Jornal Gazeta do Povo de Curitiba, PR, com o seguinte título: "As universidades estão deprimindo os estudantes? "de autoria de Ricardo Prado, publicada no dia 12/04/2018; e os dados apresentados como 
resultado de questionários acerca do tema na disciplina de filosofia, aplicados em duas turmas: uma do curso da área de ciências da saúde e outra do curso da área de ciências humanas da Universidade do Oeste do Paraná. O levantamento de dados focou nas respostas dadas pelos alunos que indicavam quem deles já haviam pensado em suicídio. Como resultados obteve-se o seguinte: $40 \%$ turma do curso da área de saúde e, $26 \%$ da turma de ciências humanas já havia pensado em cometer o ato de suicídio. Essa situação mostrou-se mais significativa, em termos de questionamentos e preocupações, quando uma aluna do curso de Medicina dessa Universidade se suicidou. O fato foi noticiado pela imprensa e causou uma série de manifestações dos estudantes. Houve alegações do excesso de exigências e da falta de humanidade quanto ao tratamento dado por alguns professores. Houve também questionamentos sobre o papel da instituição no sentido de criar programas de apoio psicossocial para atender aos estudantes em situação de risco, mas também houve manifestação de apoio à instituição e em defesa dos professores.

Há outros exemplos relacionados ao suicídio nas universidades. Em notícia veiculada no dia 06 de setembro de 2019 relata que, "em 2017, ganhou repercussão o que ficou conhecido como "surto de suicídio" na USP, quando seis alunos do curso de medicina tentaram se matar. Nessa mesma universidade, mas no ano seguinte, quatro alunos tiraram a vida em apenas dois meses. Esse texto também relata que em Viçosa, foi registrada a morte de uma aluna da UFV, em 2018. " (ASPUV,2019).

É uma situação recorrente, pois recentemente, nos meses de maio e junho de 2021, três estudantes da USP cometeram suicídio (FOLHA UOL,2021). São fatos que estão presentes nas universidades e precisam ser pesquisados e analisados para que ações de prevenção sejam tomadas.

O pesquisador em Saúde Pública c, da edição do dia 03 de agosto de 2021, afirmou

A universidade, como a sociedade em geral, está estruturada em um processo crescente de produtivismo e cobrança e isso aparece como causa central de ansiedade e sofrimento na pesquisa. A universidade está inserida nesse contexto amplo da sociedade que diz sobre todo mundo desempenhar ao máximo, com agilidade. A exigência não se dá só objetivamente com a entrega de um trabalho, mas sobre o quanto você se dedicou àquilo, como uma espécie de romantização dessa autoexploração (Carta Capital, 2021).

Nesse contexto, cabe lembra a afirmação de Montenegro e Alves (1999) que, se referindo a produção na área do conhecimento, cita a "era do publish or perish" - ou publicar ou perecer (p. 159). Ao que tudo indica essa condição estabelece ao pesquisador que a sua existência e reconhecimento acadêmico está determinada pela lógica da produção. Portanto, se pode compreender que somente sobrevive aquele que produz, ou seja, para sobreviver, obrigatoriamente, tem que atender a lógica do órgão de fomento que está vinculado ao sistema. Se não produz está morto. Essa afirmação pode ser compreendida na forma simbólica ou real, mas para o pesquisador é a sua realidade, pois, com certeza é o seu cotidiano, expresso como resultado de seu trabalho.

Parece que pelas colocações de Thiago Marques Leão, pesquisador da USP, essa mesma premissa de cobrança insana e desmedida é repassada para os estudantes. Segundo este, "a ideia de que estar na universidade é se descabelar, virar a noite, isso é muito problemático. Digo isso porque novamente, o que é de natureza coletiva, é levado para o individual, como se esse jovem não tivesse se esforçado o suficiente" (Carta Capital, 2021).

Ao que parece, esse nível de exigência acarreta ansiedade, estresse e frustrações que nem todos suportam e, alguns, acabam cometendo o suicídio, pois nem todos procuram ajuda e assim tendem a resolver sozinhos as angústias diante de suas perspectivas de vida. Nesse aspecto, o mesmo pesquisador afirma que "a universidade tem que entender que essa cobrança não é razoável, principalmente quando se considera a situação de estudantes que não têm uma rede de segurança social suficiente para que eles possam produzir como ela espera" (Carta Capital, 2021).

Entretanto, Thiago Marques Leão faz um alerta afirmando que 
[...] agora, é importante considerar que os professores estão passando pelo mesmo processo dos estudantes. Não se fala, mas muitos cometem suicídio, estão deprimindo, procurando ajuda psicológica, psiquiátrica. Os professores universitários também estão cada vez mais assumindo uma série de obrigações que não tinham e vivem sob a mesma lógica de produção acadêmica, desempenho profissional. (Carta Capital, 2021).

Enfim, tudo isso demonstra que é necessário discutir e refletir sobre a temática do suicídio no espaço da universidade.

\section{Metodologia}

Esta pesquisa surgiu devido a exigência do estágio de Ensino Superior como evento obrigatório do Programa de PósGraduação em Educação em Ciências e em Educação Matemática - PPGECEM. A pesquisa foi aprovada com o Parecer 2.858.032 do Comitê de Ética da Unioeste.

Trata de uma pesquisa qualitativa, cuja metodologia consiste em pesquisa bibliográfica e de campo. A pesquisa bibliográfica foi realizada por meio de consulta em livros de autores que discutem a temática do suicídio e de pesquisa de artigos em banco de dados de periódicos da Capes e em site da OMS - Organização Mundial da Saúde.

O critério utilizado para a inclusão dos participantes nessa pesquisa foi a matricula dos alunos, de ambos os cursos, na disciplina de Filosofia. Para a pesquisa de campo foi utilizado questionário com perguntas semi-estrturadas. Foram aplicados em torno de setenta questionários em discentes do primeiro ano de um curso da área da saúde e de um curso da área da educação. Os dados formam compilados e expressos em percentuais. Utilizou-se como referências para fundamentar a metodologia os autores Denzin e Lincoln (2006), Michaliszyn, Tomasini (2012) e Gil (2014), Gil (2007).

Os artigos da base de dados dos Periódicos Capes (2021) foram selecionados no espaço temporal de 2011 a 2020, tendo como critério a revisão por pares e o descritor de pesquisa "suicídio". A partir dos critérios adotados, obteve-se, como resultado, 3102 artigos que abordam o tema suicídio, assim distribuídos: 2011(261); 2012 (343); 2013 (309); 2014 (310); 2015 (304); 2016 (309); 2017 (369); 2018 (333); 2019 (272) e 2020 (292). No período de 10 anos que compreende a pesquisa na base de dados a média anual aproximada foi de 310 artigos. A quantidade de produção de artigos relacionadas ao tema suicídio tem variações de ano para ano. Apenas em 2012 é que houve um acréscimo significativo na produção de artigos, com um aumento de cerca de $31 \%$ entre 2011 e 2012.

Também foram levantados dados no site da OMS (2018), objetivando verificar a taxa de suicídio em relação à renda per capita de alguns países. A Tabela 1 apresenta a taxa de suicídios de forma crescente, permitindo visualizar a taxa/renda per capita. 
Tabela 1 - Taxa de suicídio por renda per capita.

\begin{tabular}{|l|c|c|}
\hline Países & taxa suícido. & R. per capita(dólar) \\
\hline Venezuela & 6,6 & 14500 \\
\hline Peru & 7,6 & 6571 \\
\hline Brasil & 9,7 & 15000 \\
\hline Equador & 10,7 & 6198 \\
\hline Colômbia & 11,5 & 15.396 \\
\hline Paraguai & 12,3 & 4365 \\
\hline Argentina & 15 & 14410 \\
\hline Canadá & 15,1 & 45032 \\
\hline Chile & 16 & 15346 \\
\hline Bolívia & 16,9 & 3393 \\
\hline Austrália & 17,4 & 53799 \\
\hline França & 17,9 & 38476 \\
\hline USA & 21,1 & 56531 \\
\hline Uruguai & 26,8 & 16245 \\
\hline Suriname & 36,1 & 5900 \\
\hline Guiana & 46,6 & 4725 \\
\hline Rússia & 48,3 & 10743 \\
\hline
\end{tabular}

Fonte: Dados elaborados pelos autores a partir de pesquisa na internet, utilizando o descritor taxa de suicídio e renda per capita por país.

Os dados apresentados não demonstram de forma evidente a relação entre a renda per capita e a taxa de suicídio, pois a Bolívia apresenta uma renda per capita de US 3.393,00 para uma taxa de 16,9 suicídios, enquanto os Estados Unidos, que possuem a maior renda per capita, US 56.531,00, apresenta taxa de 21,1 suicídios para cada 100 mil habitantes. Por outro lado, tem-se a Guiana, com renda per capita de US 4.725,00 para uma taxa de 46,6 suicídios para cada 100 mil habitantes. Diante desses dados, pode-se inferir que a condição de riqueza ou pobreza do país pode ter alguma influência na taxa de suicídio, entretanto, parece não existir uma relação direta entre riqueza, pobreza e taxa de suicídio.

Pelos dados apresentados, observa-se que cada povo tem uma taxa de suicídio própria. Para Durkheim (2000), esses índices reproduzem o ritmo da vida social e, de alguma forma, estão vinculados a questões estabelecidas pelas relações entre pessoas nos diversos grupos sociais, tais como a família, a igreja, o casamento e o divórcio, entre outros, que podem influenciar os índices expressos nas taxas de suicídio. Nesse contexto, a renúncia, a dissolução ou o enfraquecimento de vínculos do sujeito com esses grupos de pertencimento podem evoluir para a finitude da vida pelo ato do suicídio.

A pandemia do Covid-19 também foi um evento que somou para o aumento dos casos de suicídio em diversos países. em uma notícia veiculada no dia 27 de julho de 2020, no site https://www.segs.com.br/demais/243193-aumento-de-32de-suicidios-durante-a-quarentena-alerta-para-preocupacao-com-a-saude-mental-na-sociedade, apresenta-se, como manchete, que "aumento de $32 \%$ de suicídios durante a quarentena alerta para preocupação com a saúde mental na sociedade".

A página que noticia a manchete cita uma pesquisa realizada em Michigan e divulgado pelo Pine Rest Christian Mental Health Services, um hospital psiquiátrico e profissional de saúde comportamental, nos Estados Unidos, relatou que o suicídio aumentou em 32\% durante a quarentena por causa da pandemia mundial causada pela Covid-19. São diversos fatores que podem influenciar nesse índice e, que são consequências diretas da pandemia. Por exemplo, a perda do trabalho, a falta de perspectiva e o sentimento de vulnerabilidade frente a instabilidade econômica, a separações de casais, a perda de companheiros, familiares e amigos, etc. 
No Brasil não foi diferente, pois a mesma página apresenta o seguinte: No Brasil, um estudo realizado pela Universidade do Estado do Rio de Janeiro (UERJ) mostra um crescimento de 90,5\% nos casos de depressão entre os brasileiros desde o início do isolamento social. A pesquisa reuniu respostas de 1.460 pessoas de 23 estados do país.

$\mathrm{O}$ estudo também aponta crescimento nos casos de ansiedade e estresse agudos. No caso da ansiedade aguda, a proporção foi de $8,7 \%$ para $14,9 \%$, e no caso do estresse, foi de $6,9 \%$ para $9,7 \%$.

A busca pela ajuda psicológica e psiquiátrica também aumentou durante a pandemia do covid-19 e tende a crescer no pós-pandemia. a preocupação com as sequelas causadas pelo coronavirus fez com o senado nacional elaborasse um projeto que está em tramitação no congresso e que aprova o atendimento psicológico e psiquiátrico no sus para pacientes afetados pela pandemia (BRASIL, 2021). dentre as diversas sequelas, citam-se que uma delas é a depressão.

A partir desses dados, colocações e questionamentos mencionados neste texto, objetiva-se propiciar algumas reflexões acerca do ato do suicídio, como último ato executado pelo próprio sujeito no cenário da vida. Para tanto, buscar-se-á discutir questões que sirvam de parâmetros para refletir sobre as possibilidades de ampliar a compreensão sobre o fato/ato de pôr fim à vida, bem como criar perspectivas com a finalidade de estimular discussões acerca do assunto em todos os espaços sociais, mas, principalmente, no espaço escolar e acadêmico, na esperança de poder, minimamente, promover a prevenção.

\section{Resultados e Discussão}

\section{Diferentes abordagens acerca do ato do suicídio}

De acordo com Tejeda (2011), a decisão de viver ou de morrer é, nos suicidas, a sua última decisão que está a se consolidar. Em função dessa condição, o autor considera importante refletir sobre essa tomada de decisão nas pessoas a partir de aspectos relacionados à idade, ao momento de vida, à condição de saúde/doença, bem como ao seu estado emocional.

Essa compreensão é ratificada por Maqueo e Cervantes (2016), que afirmam o caráter multifatorial do ato suicida. Da mesma forma, São Pedro (2017) afirma que "[...] o fenômeno suicídio deve ser tratado conforme a sua complexidade e sua dimensão sócio-histórica, a fim de que sejam levados em consideração os contextos que ensejaram a sua causa e não apenas a perspectiva biológica/psicológica/psiquiátrica" (São Pedro, 2017, p. 1). As colocações dos autores nos remetem à ideia de complexidade em que está envolto o ato do suicídio, bem como da decisão para a execução do ato de terminar com a própria vida.

Tejeda (2011) assinala que a tomada de decisão está vinculada a várias perspectivas por parte do sujeito e que a maneira pela qual se tomam decisões, boas ou más, demonstram o quanto é complexo o ato de se decidir ou não, já que essa opção pode ser a sua última decisão. Contudo, a última decisão também é uma escolha que pode fazer a diferença entre a vida e a morte. Nesse aspecto, São Pedro (2017) cita como conceitos o seguinte:

O suicídio é um ato intencional de um sujeito para aniquilar sua própria vida. O ato suicida é caracterizado por ser a lesão causada independente de seu grau de intenção, compreendendo as tentativas de suicídio. A ideação suicida está incluída no comportamento suicida, o qual inclui também a tentativa de suicídio e o suicídio consumado (São Pedro, 2017, p. 1).

Tejeda (2011) corrobora o conceito, ao afirmar que:

A palavra suicídio vem do latim sui caedere: sui, que significa a si mesmo, e caedere, que significa matar, isto é, matar a si mesmo. É mencionado que esta palavra foi usada pela primeira vez por Abbe Desfontaines em 1737, mas é ao longo da história da humanidade que o suicídio tem sido estudado em várias áreas, tais como as filosóficas, sociais, médicas e psicológicas (Tejeda, 2011, p. 124). 
A fim de ampliar as possibilidades de tentar compreender a decisão pelo ato de suicídio, serão apresentados, a seguir, aspectos relacionados a questões filosóficas, sociológicas e psicológicas.

\section{Aspectos filosóficos}

Tejeda (2011) cita os aspectos filosóficos, e destaca que

Do ponto de vista filosófico, o tema do suicídio é abordado com aceitação e profundidade, uma vez que é considerado um elemento fundamental dentro do campo da filosofia. A este respeito, acredita-se que muitas pessoas morrem porque pensam que a vida não vale a pena ser vivida, enquanto outras se deixam matar pelas idéias ou ilusões que lhes dão motivos para viver e que, por sua vez, eles se tornam razões para morrer (Tejeda, 2011, p. 124).

Nesse contexto, Tejeda (2011) apresenta como um dos exemplos, as afirmações de Albert Camus, para quem:

O suicídio é uma esperança para parar de sofrer, quando a vida é pensada e sentida como um sofrimento muito grande e interminável. Para alguns, pode ser ilógico, no entanto, na vida, é quase impossível ser lógico sempre e até o fim (Tejeda, 2011, p. 125).

A citação remete à ideia de como o sujeito percebe o mundo e a sua existência nele, que se expressa numa possível visão filosófica da vida, na qual a vida é apenas sofrimento. Portanto, não vale a pena viver, sendo a melhor solução, para eliminar o sofrimento, a morte. Por outro lado, pode-se compreender que a morte promove a liberdade em relação ao sofrimento. Nesse sentido, morrer pode significar a perspectiva de outra existência, de outra "vida", livre do sofrimento.

Este autor também cita que o estoicismo - corrente filosófica surgida na Grécia antiga, difundida pelos filósofos Zenão de Cítio, Cleantro de Assos, Crisipo de Solis - sustenta que "[...] o suicídio é apenas lícito quando é obra da virtude, mas que o ato virtuoso não pode ser esporádico, mas deve resultar de um estado da alma como um todo" (Tejeda, 2011, p. 125). O autor exemplifica essa perspectiva de compreensão filosófica sobre o ato de suicídio ao afirmar que, em certas circunstâncias de existência, o suicídio, é lícito e aceitável. Isso pode ocorrer diante de situações em que a pessoa está subjugada a uma situação de doença que promove a ausência dos meios mínimos de subsistência, sendo, nesse caso, impossível continuar com uma vida normal.

Tejeda (2011), para concluir, afirma que

O estoicismo é uma doutrina da liberdade fundada na possibilidade da morte livre, que não é de forma alguma idêntica ao suicídio, já que, na maioria dos casos, o suicídio é um produto da paixão. É importante notar que, para os estóicos, o suicídio não é apenas uma liberdade, mas também uma liberdade para escolher (Tejeda, 2011, p. 126).

Na perspectiva de compreensão dessa corrente de pensamento, o homem pode morrer quando ele escolher. A sua consciência é que procede a sua escolha. Nesse sentido, ele é livre para viver e morrer, sendo assim, dar fim à vida de forma consciente não significa, necessariamente, cometer suicídio.

\section{Aspectos sociológicos}

Basicamente, todos os autores que pesquisam e produzem material científico acerca do suicídio mencionam aspectos sociológicos como fatores que podem desencadear a tomada de decisão para o ato de suicídio. Entretanto, Durkheim (2000) trata a questão do suicídio como um acontecimento predominantemente social.

Algumas questões são levantadas por Durkheim (2016) para refletir sobre a questão do suicídio, pois ele parte da ideia de que grande parte das causas dos suicídios não estão nas pessoas que cometem o ato; elas são externas, pois a sua análise é 
realizada a partir de uma concepção sociológica. Nesse sentido, as questões levantadas pelo autor procuram expressar que, como pano de fundo do ato, existe o contexto social que pode estar gerando todo o processo de desencantamento pela vida no sujeito suicida. Assim, Durkheim (2016) afirma que existe uma tendência de aumento dos casos de suicidas quando alguma crise afeta temporalmente o estado social.

Aliás, torna-se necessário lembrar que o termo crise, nos últimos anos, tem sido utilizado em todos os espaços sociais, estando associado aos discursos sobre questões das áreas da educação, da saúde, das finanças, da política, do núcleo familiar, de produtos naturais, como água e petróleo, entre outras. Além disso, aparece em questões pertinentes a ética e moralidade, afetando todas as classes sociais, em maior ou menor graus. Poderia se questionar se é uma crise social que afeta todas as instituições e as pessoas ou é uma crise mais específica, tendo como foco a própria existência. Ou as duas coisas ao mesmo tempo? Quem afeta quem? O que fazer diante desse cenário?

Essas reflexões permitem, minimamente, compreender o que Durkheim (2016, p. 15) afirma: “[...] o suicídio evolui em ondas de movimentos distintos e sucessivos. Se desenvolvem durante um tempo, reduzem depois, para voltar a crescer novamente". Nesse sentido, o autor afirma que cada sociedade tem, em determinado momento de sua história, uma aptidão para o suicídio.

Essa condição tratada por Durkheim (2016) expressa a taxa de mortalidade causada por suicídio em diferentes regiões do planeta. Pode-se, portanto, inferir que o ato de suicídio ocorre em todos os países, independentemente da severidade das crises, pois não se pode afirmar, com certeza, o quanto ou em que grau a crise das instituições contribui para o aumento da taxa de suicídio.

Durkheim (2000), a partir de sua análise sociológica do suicídio, afirma que:

Seja qual for o prazer que o homem tenha em agir, em se mover, em fazer esforço, é preciso que ele sinta que seus esforços não são vãos e que andando ele avança. Ora, não avançamos quando não andamos na direção de nenhum objetivo ou, o que dá na mesma, quando o objetivo na direção do qual andamos está no infinito. Quando a distância a que estamos dele continua a mesma por mais que tenhamos caminhando, é como se nós tivéssemos movido esterilmente, sem sair do lugar (Durkheim, 2000, p. 314).

Face a essa condição, estabelecida e presente no contexto social pensado por Durkheim (2000), o autor conclui ao destacar que "[...] perseguir um fim inacessível por hipótese é, portanto, condenar-se a um estado perpétuo de descontentamento" (Durkheim, 2000, p. 314). A partir dessa perspectiva, pode-se compreender que o sujeito, dessa forma, percebe-se como alguém que não pertence a lugar nenhum, está isolado, sozinho. Assim, estando estabelecida essa condição, ela poderá desencadear a decisão pelo ato de suicídio.

Durkheim (2016) também ressalta que a desigualdade social amplia a coerção social sobre o sujeito. Nesse contexto, pode-se inferir que a luta pela sobrevivência e, em última instância, pelo reconhecimento social, torna-se cada vez mais severa e determinante, podendo produzir como resultado o êxito ou o fracasso. O êxito representaria a conquista, o reconhecimento e a própria validez social. Apenas para exemplificar a importância dessa condição para a existência humana, destaca-se que: "Não estamos em condições de pensar, sentir, querer, e atuar sem que diante de nós haja algum objetivo. [...] a vida psíquica do homem tende, como o personagem criado por um bom dramaturgo, em direção do seu V (quinto) ato" (Vigotski, 1997, p. 15).

Ao que parece, a tendência de todas as pessoas é buscar para a sua vida a realização do seu $\mathrm{V}$ ato, ou seja, chegar ao ponto mais alto daquilo que sempre desejou e sonhou. Portanto, o significado do $\mathrm{V}$ Ato pode ser tão diverso quanto a diversidade humana. Assim, na profissionalização ou formação se pode alcançar êxito ou fracassar na sua realização. Neste caso, o fracasso poderá desencadear o processo que o levará ao ato de suicídio. Diante dessas condições impostas pelo social e estando as pessoas sujeitadas às possibilidades de êxito ou de fracasso, Durkheim (2000, p. 315) afirma que "[...] estamos presos a vida apenas por um fio muito tênue e que a cada momento pode ser rompido". 
Quando se trata de aspectos do comportamento humano, deve-se considerar que o sujeito pode aceitar o fracasso, resignar-se diante de situação imposta pelo social ou não aceitar nenhuma dessas possibilidades. Essa ideia é ratificada pela citação de Abbagnano (1989), que afirma: “[...] a perturbação psíquica nasce do sentimento de uma possibilidade nula, ou seja, da ausência de qualquer possibilidade concreta, mesmo a do fracasso, que o indivíduo possa escolher ou aceitar" (Abbagnano, 1989, p. 20).

\title{
Aspectos psicológicos
}

Segundo dados da OMS (2016), em mais de 90\% dos casos de suicídio ocorridos existe algum transtorno mental presente, tais como: transtornos depressivos (36\%), transtorno pelo uso de álcool (23\%), esquizofrenia (14\%) e transtornos de personalidade (10\% dos casos). - Convém destacar que os transtornos mentais são abordados como transtornos emocionais ou psicológicos. - Em função dessa condição, torna-se importante apresentar o conceito de transtorno mental do DSM-V (Diagnostical and Statistical Manual of Mental Disorders - Fifth Edition, publicado pela APA- American Psychiatric Association), que afirma:

\begin{abstract}
Um transtorno mental é uma síndrome caracterizada por perturbação clinicamente significativa na cognição, na regulação emocional ou no comportamento de um indivíduo que reflete uma disfunção nos processos psicológicos, biológicos ou de desenvolvimento subjacentes ao funcionamento mental. Transtornos mentais estão frequentemente associados a sofrimento ou incapacidade significativos que afetam atividades sociais, profissionais ou outras atividades importantes. Uma resposta esperada ou aprovada culturalmente a um estressor ou perda comum, como a morte de um ente querido, não constitui transtorno mental. Desvios sociais de comportamento (p. ex., de natureza política, religiosa ou sexual) e conflitos que são basicamente referentes ao indivíduo e à sociedade não são transtornos mentais a menos que o desvio ou conflito seja o resultado de uma disfunção no indivíduo, conforme descrito (DSMV, APA, 2014, p. 20).
\end{abstract}

Segundo o DSM-V (2014), alguns transtornos podem ter maior significância na ideação suicida, nas tentativas e no próprio ato suicida. Os transtornos citados pelo DSM- V, neste caso, são: TDAH ( Transtorno de Déficit de Atenção e Hiperatividade); Espectro da Esquizofrenia e Outros Transtornos Psicóticos; Transtorno Bipolar; Transtorno Disruptivo da Desregulação do Humor; Transtornos Depressivos; Transtorno Disfórico Pré-menstrual; Transtorno Depressivo Induzido por Substância/Medicamento; Transtornos de Ansiedade (Transtorno de Pânico); Transtorno Obsessivo-compulsivo; Transtorno Dismórfico Corporal; Transtorno de Estresse Pós-traumático; Transtorno Dissociativo de Identidade; Transtornos Alimentares; Transtorno por Uso de Álcool; Transtornos Relacionados a Substâncias e Transtornos Aditivos; Transtorno Relacionado ao Álcool Não Especificado; Transtorno por Uso de Opioides; Abstinência de Outra Substância (ou Substância Desconhecida); Transtorno da Personalidade Antissocial; Transtorno da Personalidade Borderline.

O DSM-V (2014) destaca a existência de comorbidades concomitantes aos transtornos citados, que podem potencializar a ideação suicida, as tentativas e a execução do ato. Dessa forma, em maior ou menor graus, todos esses transtornos apresentam índices de suicídio.

A publicação da OMS (2000), denominada "Prevenção do suicídio - um manual para profissionais da saúde primária", destaca que os maiores índices de suicídio estão relacionados, em ordem decrescente, aos seguintes quadros de patologia: "depressão (todas as formas); transtorno de personalidade (antissocial e borderline com traços de impulsividade, agressividade e frequentes alterações do humor); alcoolismo (e/ou abuso de substância em adolescentes); esquizofrenia” (OMS, 2000, p. 5).

É importante destacar que o DSM-V (2014) tem como finalidade principal fornecer parâmetros clínicos para que o profissional da saúde possa realizar um diagnóstico adequado, objetivando um tratamento mais eficiente para os casos de ideação ou tentativas de suicídio que afetam todas as idades. O DSM-V chama atenção para a prevalência, em termos de tentativas, por idade e gênero. 
Tejeda (2011) destaca a fase da adolescência afirmando que a

[...] adolescência, juntamente com situações de conflito, e a soma de problemas não resolvidos, são fatores que permitem entrar em um estado de desesperança e pensar em suicídio como forma de acabar com o tormento que faz sofrer (Tejeda, 2011, p. 133).

Com relação a esse aspecto, Tejeda (2011) cita alguns postulados de Sneidman, citados por Chávez-Hernández at al. (2010) os quais são expressos da seguinte maneira:

1. Suicídio é a busca de uma solução para um problema que gera sofrimento; 2. É uma maneira de cessar a consciência, não necessariamente a vida; 3. Dor que não controlamos é um risco de suicídio para acabar com essa dor incontrolável; 4. Para o suicídio, o ato é sempre lógico; 5. A emoção do suicídio é desespero e impotência; 6. Sua atitude: ambivalência. Viva e morra ao mesmo tempo, mas um dos sentimentos surge mais fortemente que o outro; 7. O estado cognitivo é a "visão de túnel"; 8. Suicídio é um ato de comunicação interpessoal com "pistas", por meio de sinais, que o executor deixou (Tejeda, 2011, p. 133).

Ainda na abordagem dos aspectos psicológicos, Tejeda (2011) destaca a análise sobre o suicídio, pontuando o entendimento e as possíveis explicações sobre esse tema, apontadas por Erich Fromm (1900-1980), Carl G. Jung (1875-1961), Sigmund Freud (1956-1939), Jacques Lacan (1901-1981).

Quanto aos traços de personalidade de comportamento suicida, Tejeda (2011) verificou em suas pesquisas que, para os casos de crianças e adolescentes, há duas características: as crianças apresentavam alto grau de fantasia e baixa tolerância à frustração; e, no caso dos adolescentes, foram encontrados os traços de impulsividade, rigidez, ambivalência que estão presentes na população em geral. A baixa tolerância à frustração também aparece como uma característica no grupo de adolescente.

Os autores Gonçalves et al. (2011) corroboram os apontamentos de Tejeda, ao destacar como indicadores de comportamento suicida:

[...] desespero, pensamentos negativos, baixo auto-conceito, insônia, concentração diminuída, impulsividade, agressividade, anedonia, sentimento de culpa, perfeccionismo, poucas razões para viver, os quais, de forma frequente, são encontrados nos jovens com comportamento suicida (Gonçalves; Freitas; Siqueira, 2011, p. 155).

Além disso, Gonçalves, Freitas e Siqueira (2011) destacam, como fatores de riscos que podem evoluir para o ato de suicídio, a presença de ideação suicida, história de tentativas de suicídio, desesperança e falta de projetos de vida, quadros ansiosos, acontecimentos de vida negativos, suporte familiar e social, neste caso, fracos ou insuficientes, padrões de vinculação inseguros, presença de stress em alto grau e disponibilidade do método suicida, sendo que esta condição favorece a execução do ato.

Outra questão que tem sido discutida é o cybersuicídio entre adolescentes por meio da rede de computadores. Dieu e Kahan (2018) afirmam que

A influência da Internet trouxe consigo a aparência de novo tipo de suicídio: Cybersuicídio. Este conceito refere-se à ação de tirar a própria vida, motivado pela influência de páginas da web com conteúdo de ajuda, influência ou motivação para cometer suicídio (sites pró-suicídio), salas de chat, jogos mortais e fóruns de Internet entre outros. Ele destaca a relação entre o comportamento suicida, a Internet e redes sociais como um canal de informação e encontro em usuários com ideação suicida (Dieu \& Kahan, 2018, p. 3).

Um dos jogos disponíveis na Internet e que produziu atos de suicídio entre adolescente foi a baleia azul (BlueWhale). Informações disponíveis na internet apontam que 
[...] a baleia azul, Blue Whale, é um "jogo" inventado por um jovem russo (21 anos) Philipp Budeikin, que atualmente está preso em São Petersburgo. A idéia do jogo era "limpar a sociedade" e agora há centenas de suicídios entre adolescentes vulneráveis que foram desencadeados por esta série de provas. É um desafio em 50 dias em que os adolescentes têm que superar uma série de desafios e enviá-los para redes sociais com o rótulo "I_am_whale" através de imagens ou vídeos. Esses testes são formados por uma série de desafios, incluindo autolesão (tatuagens de uma baleia, cortes na pele ...), privação de sono, ouvir música psicodélica ou assistir a vídeos assustadores enviados pelo "mentor" (curador) que tem todos os jogadores (Bluewhale).

Outra questão importante a destacar é a reflexão do autor Lipovetsky (2000), citado por Dieu e Kahan (2018), que trata sobre o Narcisismo e a exposição nas redes sociais. Segundo Dieu e Kahan (2018), citando Lipovetsky (2000), o narcisismo na sociedade atual está determinado pelo interesse e pela predominância do viver "aqui e agora", ou seja, viver se resume a tudo aquilo que é imediato.

Parece que tal situação, como uma experiência vivenciada, estabelece para a pessoa a condição de não ter perspectiva de continuidade, acarretando a redução, de forma significativa, de objetivos, metas e projetos que poderiam dar um sentido a existência pessoal e/ou profissional. Parece que nessas condições a pessoa deixa de ter um sentido de existência, de vida, em termos de sonhos e de possíveis realizações a serem conquistadas no futuro.

Nessa perspectiva, Lipovetsky (2000) afirma que “[...] existe uma primazia do ato de comunicação sobre a natureza do comunicado, a indiferença pelo conteúdo. O que importa é se expressar seja qual for a natureza da mensagem, o prazer certo e narcisista de se expressar para nada, para si mesmo" (Lipovetsky, 2000, p. 15). O autor destaca, ainda, que o criador da mensagem também é o orador.

Essas questões remetem à ideia de que o criador precisa visualizar quantas curtidas a sua mensagem alcançou para sentir-se valorizado. O reconhecimento é apenas virtual. Se esse reconhecimento não ocorre, pode-se criar o sentimento de fracasso. Aqui, convém lembrar que uma das características da personalidade do adolescente é a baixa tolerância à frustração, como já mencionado anteriormente.

Por outro lado, pensando no quanto é fluida, rápida e intensa a produção de conteúdos disponíveis na rede de internet, o sujeito, para manter-se numa perspectiva de buscar consolidar o seu valor, em termos de reconhecimento ou popularidade, provavelmente terá que se tornar quase que escravo do processo de criação e postagem, objetivando manter-se atualizado para os seus seguidores.

Nesse aspecto, segundo Lipovetsky (2000, p. 10), a sociedade atual estabelece “[...] o consumo da própria existência através da proliferação das mídias de massa, do lazer, das técnicas relacionais, o processo de personalização gera o vácuo em tecnicolor, a imprecisão existencial na e pela abundância de modelos".

O que foi exposto até agora pode criar possibilidades de reflexões acerca do suicídio e demonstrar o quanto é complexa essa questão. Entretanto, independentemente de o suicídio ser visto como um acontecimento presente na história humana e de ser caracterizado como um evento multifatorial, torna-se necessário ampliar as possibilidades de discutir, pesquisar e divulgar trabalhos científicos para, minimamente, buscar promover a proteção das pessoas que possuem comportamento suicida.

\section{Considerações Finais}

Espera-se que este texto possa criar possibilidades de refletir sobre o tema suicídio, bem como ampliar a compreensão sobre a dinâmica estabelecida em função das crises relacionadas aos aspectos biopsicossociais que podem ser fatores relevantes para desencadear todo o processo que poderá levar à tomada de decisão do ato suicida.

É necessário refletir, também, sobre o fato de que somente quem conhece as razões que levam a essa tomada de decisão de tirar a própria vida é o sujeito, que é o próprio agente desse ato. Nesse sentido, é necessário que todos estejam 
cientes de que é inviável, para os familiares, professores e/ou profissionais, atuar como se fossem sombras das pessoas que possuem comportamentos com tendências suicidas. Portanto, por mais que se possam desenvolver estudos acerca do suicídio e compreendê-lo em sua totalidade, tornam-se limitadas as medidas para evitar que o ato possa ser efetivado.

De qualquer forma, se houver compreensão de que o ambiente pode ser um fator desencadeador do processo que leva à produção de pensamentos suicidas e de execução do ato, torna-se necessário questionar se o ambiente universitário, visto como um espaço de confronto de ideias, de reflexões sobre a existência humana, de realização de sonhos ou de frustrações e, portanto, de crescimento pessoal e profissional, estará, devido a todas essas exigências, causando estímulos capazes de desestruturar todas as expectativas de continuidade da vida de uma parte significativa de estudantes.

Diante desse contexto, caberia perguntar se o espaço da universidade não deveria ser mais acolhedor e capaz de fortalecer vínculos que promovessem a perspectiva de continuidade da vida para os jovens ingressantes no ensino superior.

Talvez uma possibilidade seja ampliar o processo de discussão, em todos os espaços sociais possíveis, ou seja, família, escolas, universidades, grupos de jovens, associação de bairros, para criar perspectivas, no sentido de minimizar o número de mortes de pessoas da família, jovens ou até de pessoas idosas pelo ato do suicídio. É possível que, quanto mais forem socializados os conhecimentos acerca do tema, melhores serão as possibilidades de desenvolver ações de cunho preventivo e, portanto, de preservação e valorização da vida. Dessa forma, esse processo mediado pela educação poderá ser um meio de salvar vidas e a universidade, nesse aspecto, em seu conjunto de atividades, deve somar esforços com a sociedade.

Sugere-se também como trabalhos futuros a produção de pesquisas no âmbito das universidades sobre:

- $\quad$ O acolhimento de alunos e o espaço de apoio ao processo de transição das mudanças e exigências que ocorrem entre o ensino médio e o ingresso dos discentes no ensino superior.

- A percepção dos alunos no ensino superior quanto as perspectivas de sucesso/frustrações na formação acadêmica e a futura vida profissional.

- A percepção dos alunos quanto a expectativa da família sobre o curso escolhido e o sucesso profissional.

- $\quad$ Aspectos emocionais dos discentes e o uso de drogas no espaço universitário.

- Políticas de prevenção sobre o suicídio desenvolvidas nas Instituições de Ensino Superior (IES).

\section{Referências}

Abbagnano, N. (1989). A Sabedoria da Filosofia - Problemas da nossa vida. Tradução: Efrain Alves Filho. Ed. Vozes

ANAMT. (2018). Associação Nacional de Medicina do Trabalho. https://www.anamt.org.br/portal/2019/09/02/setembro-amarelo-acoes-para-valorizacao-davida-e-prevencao-ao-suicidio/

ASPUV. (2021). Setembro amarelo acende discussão sobre o suicídio nas universidades. website da Aspuv. https://aspuv.org.br/setembro-amarelo-acendediscussao-sobre-suicidio-nas-universidades/

Bluewhale. (2021). A baleia Azul. https://nuevastecsomamfyc.wordpress.com/tag/blue-whale/

Brasil (2021). website do Senado https://www12.senado.leg.br/radio/1/noticia/2021/04/07/senado-aprova-atendimento-psicologico-e-psiquiatrico-no-sus-parapacientes-afetados-pela-pandemia

CAPES (2021). website do Periódicos Capes http://www.periodicos.capes.gov.br/

CARTA CAPITAL (2021). website https://www.cartacapital.com.br/educacao/suicidios-na-usp-a-pandemia-nao-e-a-unica-razao-para-o-sofrimento-psiquicodos-estudantes/

Chávez-hernández, A. M., Leenaars, A. A. Edwin, S. Sneidman y la suicidología moderna. website http://www.scielo.org.mx/scielo.php?script=sci_arttext\&pid=S0185-33252010000400008.

Denzin, N. K., Lincoln, Y. S. A disciplina e a prática da pesquisa qualitativa. In: Denzin, N. K., Lincoln, Y. S. (Orgs.). O Planejamento da pesquisa qualitativa: teorias e abordagens. Porto Alegre: ArtMed, 2006, p. 15-41. 
Dieu, F., Kahan, E.. Cibersuicidio en adolescentes. (2018) website https://sifp.psico.edu.uy/sites/default/files/Trabajos\%20finales/\% 20Archivos/cibersuicidio_en_adolescentes.pdf.

DSM-5. APA. (2014). Manual diagnóstico e estatístico de transtornos mentais [recurso eletrônico]: DSM-5 / [American Psychiatric Association, Tradução: Maria Inês Corrêa Nascimento ... et al.], revisão técnica: Aristides Volpato Cordioli ... [et al.]. 5. Artmed.

Durkheim, É. (2016) El suicidio. Un estudio de sociología. Traducción: Sandra Chaparro Martínez. Titivillus: Editor digital. website http://ceiphistorica.com/wp-content/uploads/2016/04/Durkheim-\%C3\%89mile-El-Suicidio.pdf.

Durkeim, É (2000). O suicídio: estudo de sociologia. Tradução: Monica Stahel. Martins Fontes.

FOLHA UOL. (2021). https://www1.folha.uol.com.br/educacao/2021/06/suicidio-de-tres-estudantes-nos-ultimos-dois-meses-acende-alerta-na-usp.shtml

GIL, A. C. (2017). Como elaborar projetos de pesquisa. (4a ed.), Atlas.

GIL. A. C. (2014). Métodos e Técnicas de Pesquisa Social. (6a ed.), Atlas.

Gonçalves, A. M., Freitas, P. P., Sequeira, C. A. C. (2011). Comportamentos Suicidários em Estudantes do Ensino Superior: Factores de Risco e de Proteção. Millenium. http://www.ipv.pt/millenium/Millenium40/11.pdf.

IASP (2019). O suicídio pode ser evitado. https://www.iasp.info/wspd/2003_wspd.php

IBGE. (2018). Instituto Brasileiro de Geografia e Estatística. https://www.ibge.gov.br/apps/populacao/projecao/.

Lipovetski, G. (2000) La era do vacío. Ensayos sobre el individualismo conterporáneo. Tradução: Joan Vinyoli e Michèle Pendanx. Barcelona: Anagrama. http://fido.palermo.edu/servicios_dyc/blog/docentes/trabajos/6553_15813.pdf.

Maqueo, E. L.G., Cervantes, Q. H. (2016). El Estudio de la Personalidad en el Tratamiento y Prevención del Suicidio en la Población Adolescente. Catalogación en la Fuente, Biblioteca Sede de la OPS. Organización Panamericana de la Salud. Prevención de la conducta suicida. Washington, DC. https://www.researchgate.net/publication/308097031_El_estudio_de_la_personalidad_en_el_tratamiento_y_prevencion_del_suicidio_en_la_poblacion_adoles cente.

Michaliszyn, M. S., Tomasini, R. (2012). Pesquisa: orientações e normas para elaboração de projetos, monografias e artigos científicos. (7a ed.), Vozes.

Montenegro, M., Alves, V. (1999) Autoria e co-autoria: justificativa e desvios. J. Pneumol., 3(25). http://www.jornaldepneumologia.com.br/PDF/1999_25_3_5_portugues.pdf.

OMS. (2018). Suicídio é grave problema de saúde pública e sua prevenção deve ser prioridade. https://www.paho.org/bra/index.php?option= com_content\&view=article\&id=5674:suicidio-e-grave-problema-de-saude-publica-e-sua-prevencao-deve-ser-prioridade-afirma-opas-oms \&Itemid=839.

OMS. (2000). Prevenção do suicídio: um manual para profissionais da saúde em atenção primária. Organização Mundial da Saúde. https://www.who.int/mental_health/prevention/suicide/en/suicideprev_phc_port.pdf.

OPS - Organización Panamericana de la Salud (2014). Prevención del suicidio: un imperativo global. http://apps.who.int/iris/bitstream/handle/10665/136083/9789275318508_spa.pdf,jsessionid=E46657493FC4038F0FDD19FB808F6517?sequence=1.

Marín-León, L., Oliveira, H. B., Botega, N. J. (2012). Suicide in Brazil, 2004-2010: the importance of small counties. Rev. Panam. Salud publica. 32(5).

São Pedro, J. R. (2017). O suicídio enquanto um fenômeno sócio-histórico: possíveis atuações e desafios da Psicologia. In: II Congresso Brasileiro de Ciências da Saúde, 1. Realize. http://www.editorarealize.com.br/revistas/conbracis/trabalhos/TRABALHO_EV071_MD1_SA5_ID1568_30042017192612.pdf.

Tejeda, A. A. (2011). Suicídio: la última decisión. Trillas.

Vigotski, L. S. (1997). Fundamentos de defectología. Obras completas. Tomo cinco. Editorial Pueblo Educación.

WHO - (2019). World Health Organization. Suicide worldwide in 2019. https://www.who.int/publications/i/item/9789240026643 